АКУШ ШЕСТВ
ГИНЕКОЛГИЯ
Р ЕПРОДУКЦИЯ Включен в перечень ведущих рецензируемых журналов и изданий ВАК

2016 • Tом 10 - № 3

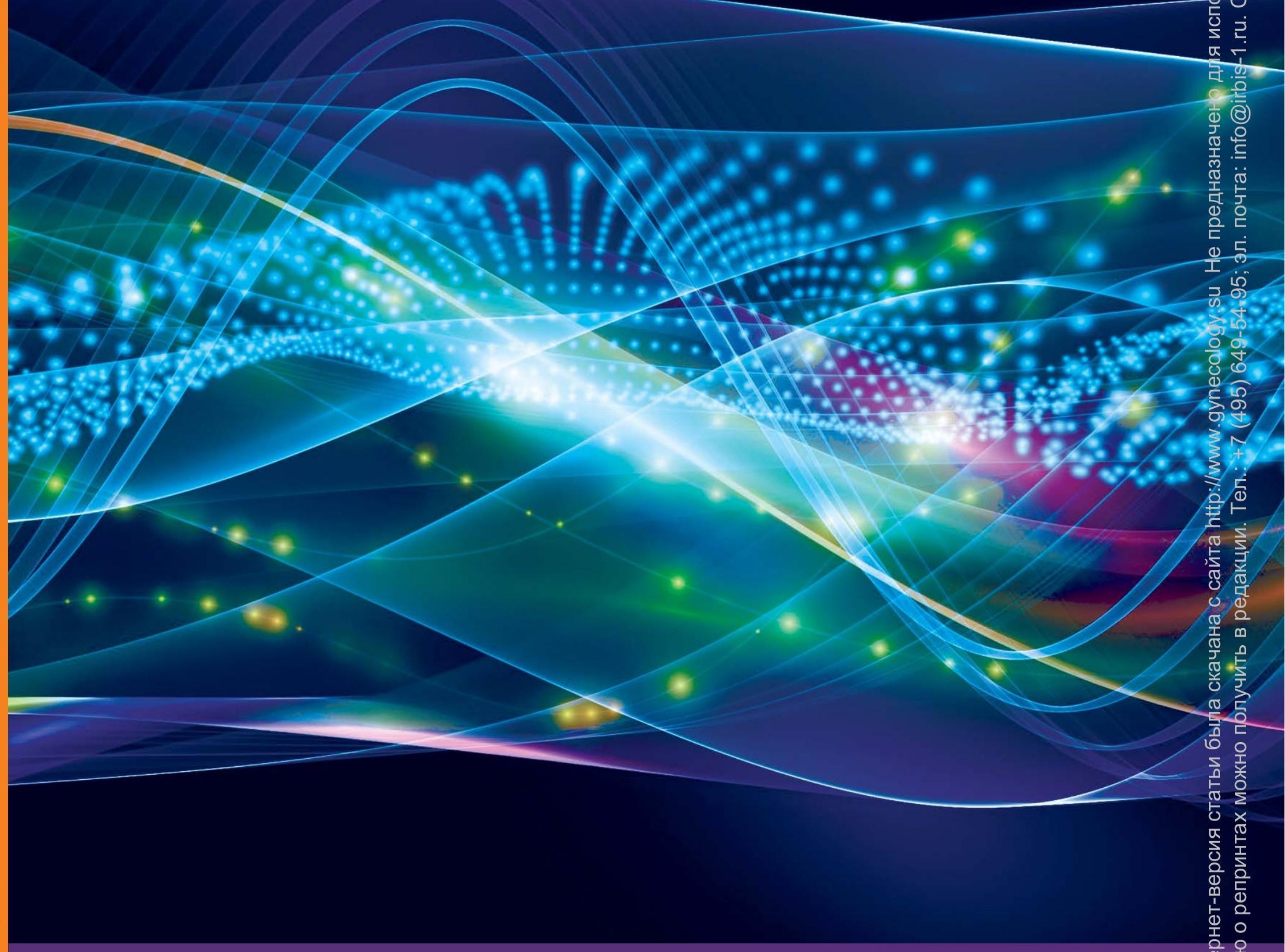

OBSTETRICS, GYNECOLOGY AND REPRODUCTIO) ISSN 2313-7347 


\section{СЛУЧАЙ ДЕСТРУКТИВНОГО}

\section{АППЕНДИЦИТА У БЕРЕМЕННОЙ СО СЛОЖНОЙ АКУШЕРСКОЙ ПАТОЛОГИЕЙ}

Хасанов А.Г. ${ }^{1}$, Журавлев И.А. ${ }^{2}$, Бадретдинова Ф.Ф. ${ }^{1}$, Мамедова 0.К. ${ }^{2}$

1 ФГБоУ ВО «Башкирский государственный медицинский университет» Минздрава России, Уфа

2 Городская клиническая больница №8 г. Уфы

\section{Резюме}

Осложнение течения беременности острым аппендицитом создает сложную акушерско-хирургическую ситуацию. Дополнительные трудности появляются, когда острая хирургическая патология возникает на фоне тяжелой акушерской патологии при больших сроках беременности. Случаи развития острого аппендицита на фоне тяжелой акушерской патологии в виде центрального предлежания и истинного приращения плаценты при многоплодной беременности в литературе не описаны. Поэтому данный клинический случай представляет практический интерес.

\section{Ключевые слова}

Острый аппендицит, центральное предлежание, истинное приращение плаценты.

Статья поступила: 22.04.2016 г.; в доработанном виде: 24.05.2016 г.; принята к печати: 14.09 .2016 г.

Конфлликт интересов

Авторы заявляют об отсутствии необходимости раскрытия фринансовой поддержки или конфрликта интересов в отношении данной публикации.

Все авторы сделали эквивалентный вклад в подготовку публикации.

\section{Для цитирования}

Хасанов А.Г., Журавлев И.А., Бадретдинова Ф.Ф., Мамедова О.К. Случай деструктивного аппендицита у беременной со сложной акушерской патологией. Акушерство, гинекология и репродукция. 2016; 3: 66-69.

\section{THE CASE OF DESTRUCTIVE APPENDICITIS PREGNANT WITH COMPLICATED OBSTETRICAL PATHOLOGY}

Khasanov A.G. ${ }^{1}$, Zhuravlev I.A. ${ }^{2}$, Badretdinova F.F. ${ }^{1}$, Mamedova D.C. ${ }^{2}$

${ }^{1}$ Bashkir State Medical University, Ufa

2 City clinical hospital №8 of Ufa

\section{Summary}

Complication of pregnancy acute appendicitis creates complex obstetric and surgical situation. Additional difficulties occur when acute surgical pathology occurs against a background of severe obstetric pathology for longer periods of 
pregnancy. The cases of acute appendicitis on the background of severe obstetric pathology in the form of a Central previa and true increment of the placenta in multiple pregnancies described in the literature. Therefore this case is actual.

\section{Key words}

Acute appendicitis, the Central presentation, a true increment of the placenta.

Received: 22.04.2016; in the revised form: 24.05.2016; accepted: 14.09.2016.

\section{Conflict of interests}

The authors declared that they do not have anything to disclosure regarding funding or conflict of interests with respect to this manuscript.

All authors contributed equally to this article.

\section{For citation}

Khasanov A.G., Zhuravlev I.A., Badretdinova F.F., Mamedova D.C. The case of destructive appendicitis pregnant with complicated obstetrical pathology. Akusherstvo, ginekologiya i reproduktsiya / Obstetrics, gynecology and reproduction. 2016; 3: 66-69 (in Russian).

\section{Corresponding author}

Address: ul. Chernyshevskogo, 160A, Ufa, Russia, 450078

E-mail: hasanovag@mail.ru (Khasanov A.G.).

\section{Введение}

Осложнение течения беременности острым аппендицитом, особенно при больших сроках гестации, создает сложную акушерско-хирургическую ситуацию [1]. Сложность ситуации, прежде всего, связана с трудностями диагностики острого аппендицита, ограниченными возможностями применения видеоэндоскопических технологий и выбором оптимальной лечебной тактики [2]. Дополнительные трудности появляются, когда острая хирургическая патология возникает на фоне тяжелой акушерской патологии. В доступной нам литературе описания случаев развития острого аппендицита на фоне тяжелой акушерской патологии мы не встречали. Поэтому данный случай представляет практический интерес.

Беременная С., 34 года (история болезни №137242993) поступила по линии скорой медицинской помощи 28.10.15 г. в 6.50 в хирургическое отделение ГКБ № 8 г. Уфы с диагнозом «острый аппендицит?». Беременность 35-36 нед. Роды - II. Угроза прерывания беременности. Из анамнеза: заболела 2 ч назад, остро, когда появились боли в правой подвздошной области, тошнота, сухость во рту. При объективном исследовании - состояние удовлетворительное. Кожные покровы обычной окраски, имеются отеки нижних конечностей. АД - 130/80 мм рт. ст. Пульс - 86 уд. в мин. Язык суховат. Живот соответствует сроку 35 нед. беременности, участвует в акте дыхания. Пальпаторно определяется локальная болезненность и напряжение в правой подвздошной области. Симптомы Щеткина-Блюмберга в правой подвздошной области, Ситковского, Бартомье-Михельсона, Воскресенского - слабоположительные. Анализы крови при поступлении: эритроциты - 3,34×1012/л; Нb - 110 г/л; гематокрит - 30,0\%; тромбоциты - 200×10\%/л. Общий анализ мочи в норме. Лейкоцитов в крови - 9,0×10\% Л. При совместном осмотре дежурного старшего хирурга и акушера-гинеколога выставлен диагноз: «острый аппендицит?» Беременность - 34-35 нед. Дихориальная диамниотическая двойня. Центральное предлежание плаценты. Угроза преждевременных родов. Водянка. Соп.: осложненный соматический анамнез. Рубец на матке. Ожирение III. Учитывая невыраженность клинической картины, малые сроки заболевания, решено вести динамическое наблюдение.

Из акушерского анамнеза выявлено: 1-я беременность в 2001 г. - замершая беременность, выполнено выскабливание полости матки, без осложнений.

2-я беременность - срочные роды путем кесарева сечения, родилась двойня с массой: $\mathrm{m} 1=3280$ г, m2=2890 г, б/0; 3-я и 4-я беременности закончились медицинским абортом без особенностей. Настоящая беременность - по счету 5-я. Течение беременности в первой половине осложнилось токсикозом, при сроке в 13 нед. - угроза прерывания (стационарное лечение), во второй половине - анемия беременных; в 23 нед. - 
кандидозный кольпит (амбулаторное лечение); 24 нед. - гиперкоагуляционный синдром; 28-29 нед. - ОРВИ 32 нед. - водянка (стационарное лечение); 34-35 нед. - ОРВИ без температурной реакции и без антибиотиков. В течение настоящей беременности наблюдался рецидивирующий кольпит. Прибавка массы тела - 7 кг.

При ультразвуковом исследовании при сроке беременности 32 нед. установлено центральное предлежание плаценты, дихориальная диамниотическая двойня. При динамическом наблюдении локальная клиника стала более выраженной и появились кровянистые выделения из половых путей, отмечалось некоторое нарастание лейкоцитов в крови - более 10,4×10\%/л.

В 9.00 ч организован консилиум врачей, во время которого выставлен диагноз: «острый аппендицит; беременность - 35 нед.; центральное предлежание плаценты; дихориальная диамниотическая двойня; тазовое предлежание I плода; нефропатия I; анемия I ст.; ожирение III степени (вес - 120 кг)».

Учитывая нарастающую клинику острого аппендицита, центральное предлежание плаценты, начавшееся кровотечение, наличие рубца на матке, решено выполнить срединную лапаротомию, родоразрешить путем операции кесарева сечения с последующей аппендэктомией.

Под эпидуральной анестезией выполнена нижнесрединная лапаротомия с иссечением старого послеоперационного рубца. Рубец на матке состоятельный. Разрез на матке - по старому рубцу. Излились светлые околоплодные воды в умеренном количестве. На 10-й мин. операции за головку без затруднений извлечен первый живой недоношенный плод мужского пола, массой 2470 г, длиной 51 см, 7-8 баллов по Апгар. Пуповина плода - около 60 см без патологии. Второй живой плод женского пола в ножном предлежании массой 2490 г, длиной 52 см, 7-8 баллов по Апгар извлечен на 11-й мин. операции. Плацента полностью занимает переднюю стенку матки и выстилает внутренний зев с переходом на заднюю стенку. В области нижней части передней стенки, в области рубца и внутреннего зева отделить плаценту от стенок не удалось - диагностировано истинное прикрепление плаценты. С учетом операционной находки, усиления кровотечения решено выполнить экстирпацию матки с трубами. Выполнена экстирпация матки. Культя влагалища обработана, ушита отдельными викриловыми швами, перитонизирована. Кровопотеря - 2000 мл. Интраоперационная гемотрансфузия в объеме 1200 мл. Червеобразный отросток резко утолщен, на поверхности фрибринозные наложения, брыжейка отечная. Операционная находка оценена как флегмонозный аппендицит. В правой подвздошной ямке - небольшое количество серозного выпота.

Произведена антеградная аппендэктомия с погружением культи отростка кисетным и Z-образными швами. После осушения брюшной полости брюшная полость ушита наглухо. Гистологическое заключение: «фрлегмонозно-язвенный аппендицит».

В раннем послеоперационном периоде больная находилась в отделении реанимации и интенсивной терапии, где проводилась интенсивная инфузионная, антибактериальная (цесалозин, гентамицин, метронидазол) и анальгетическая терапия. На 3-е сут. больная переведена в хирургическое отделение. Послеоперационный период - гладкий, заживление раны первичным натяжением, на 9-е сут. больная выписана домой.

\section{Обсуждение}

По литературным данным, острый аппендицит осложняет течение беременности у 1,5-3\% беременных и представляет большую угрозу как для матери, так и для плода. Число перинатальных потерь женщин при развитии деструктивного аппендицита может достигать до 17-50\%. Чаще всего причиной невынашивания беременности является отслойка нормально расположенной плаценты, внутриутробное инфицирование плода т.д.

В данном случае деструктивный аппендицит развился на фоне отягощенного акушерского и соматического анамнеза. Безусловно, развитие острого аппендицита этиологически не связано с беременностью. Однако осложнение беременности развитием острого аппендицита, особенно при поздних сроках беременности, создает большие трудности в своевременной диагностике и в определении акушерскохирургической тактики. В доступной нам литературе случаев развития деструктивного аппендицита на фоне тяжелой акушерской патологии при больших сроках гестации мы не встречали. Тяжелая акушерская патология в виде центрального предлежания и истинного приращения плаценты связана с неоднократными выскабливаниями полости матки и ранее выполненной операцией кесарева сечения.

Определенное негативное влияние на течение беременности оказывала хроническая инсекция шейки матки и перенесенные вирусные респираторные инфекции. Оптимальным способом хирургического лечения острого аппендицита при больших сроках беременности является нижнесрединная лапаротомия. Оптимальным способом родоразрешения в таких случаях является корпоральное кесарево сечение с последующей экстирпацией матки.

\section{Заключение}

Приведенное клиническое наблюдение представляет большой клинический интерес в плане своей редкости и сложности диагностики острого аппендицита на фоне тяжелой акушерской патологии. Своевременная диагностика и выбор оптимальной акушерско-хирургической тактики позволили сохранить жизнь как матери, так и плодов. 


\section{Литература:}

1. Стрижаков А.Н., Черноусов А.Ф., Самойлова Ю.А., Рыбин М.В. Беременность и острый аппендицит. М. 2010; 159 с.
2. Хасанов А.Г., Бадретдинова Ф.Ф., Магафуров Р.Ф., Шевченко 3.Р., Нуриева А.Р., Мамедова О.К. Вопросы акушерской тактики при остром аппендиците у беременных. Акушерство,гинекология и репродукция 2014; 8 (4): 19-23.

\section{References:}

1. Strizhakov A.N., Chernousov A.F., Samoilova Yu.A., Rybin M.V. Pregnancy and acute appendicitis [Beremennost' i ostryi appenditsit (In Russian)]. Moscow. 2010; 159 s.

2. Khasanov A.G., Badretdinova F.F., Magafurov R.F., Shevchenko Z.R.
Nurieva A.R., Mamedova O.K. Akusherstvo, ginekologiya i reproduktsiya / Obstetrics, gynecology and reproduction. 2014; 8 (4): 19-23.

\section{Сведения об авторах:}

Хасанов Анвар Гиниятович - д.м.н., профессор, зав. кафедрой хирургических болезней Башкирского государственного медицинского университета. Адрес: ул. Чернышевского, д. 160A, 450078, Уфра, Россия. E-mail: hasanovag@mail.ru.

Журавлев Игнатий Александрович - хирург-ординатор городской клинической больницы №8 г. Уфы. Адрес: ул. 40-лет Октября, Уфа, Россия, 450112. E-mail: ignatyz@mail.ru.

Бадретдинова Фларида Фуатовна - к.м.н., доцент кафедры акушерства и гинекологии института последипломного образования Башкирского государственного медицинского университета. Адрес: ул. Ленина, 3, г. Уфа, Россия, 450000. E-mail: fbadretdinova@mail.ru. Тел.+7(917)7440953.

Мамедова Офелия Камилевна - акушер-гинеколог родильного отделения городской клинической больницы №8 г. Уфы. Адрес: ул. 40-лет Октября, Уфа, Россия, 450112.

\section{About the authors:}

Khasanov Anvar Ginijatovich - MD, professor, head. Department of surgical diseases of the Bashkir State Medical University. Address: ul. Chernyshevskogo, 160A, Ufa, Russia, 450078. E-mail: hasanovag@mail.ru.

Zhuravlev Ignat Aleksandrovich - surgeon resident at City Clinical Hospital No. 8 of Ufa. Address: ul. 40-let Oktyabrya, Ufa, Russia, 450112. E-mail: ignatyz@mail.ru. Tel.: +7(927)3462993.

Badretdinova Flarida Fuatovna - PhD, Associate Professor of obstetrics and Gynecology Institute of postgraduate study of Bashkir State Medical University. Address: ul. Lenina, 3, Ufa, Russia, 450000. E-mail: fbadretdinova@mail.ru.

Mamedova Ofeliya Kamilevna - obstetrician-gynecologist at City Clinical Hospital No. 8 of UFA. Address: ul. 40-let Oktyabrya, Ufa, Russia, 450112. 